\title{
La evolución conceptual de la arqueología subacuática
}

\section{The conceptual evolution of underwater archaeology}

\author{
XAVIER NiETo \\ xnietop00@gmail.com
}

Si aceptamos el año 1950 como fecha a partir de la que el barco hundido comienza a ser considerado como un documento histórico, que debe ser investigado con metodología arqueológica, hemos de aceptar que la arqueología subacuática es una actividad científica con una corta trayectoria. Una fase inicial en la que esta disciplina ha debido definirse y crear unos estándares conceptuales, pero también técnicos. Creemos que tres arqueólogos, tres excavaciones y tres fechas marcan los hitos de una evolución conceptual que nos ha conducido a la situación actual en la que la epistemología de la disciplina parece haber llegado a ser establecida con un aceptable nivel de definición: Nino Lamboglia, con los trabajos en el pecio de Albenga en 1950; George Bass, a partir de 1961, con sus trabajos en Yassi Ada, y André Tchernia y la excavación de la Madrague de Giens, a partir de 1972.

\section{PALABRAS CLAVE}

ARQUEOLOGÍA SUBACUÁTICA, METODOLOGÍA DE LA ARQUEOLOGÍA SUBACUÁTICA, EXCAVACIÓN ARQUEOLÓGICA, EVOLUCIÓN DE LA ARQUEOLOGÍA SUBACUÁTICA

If we agree on 1950 to be the date from which a sunken ship begins to be considered a historical document, we will come to the conclusion that underwater archaeology is a scientific activity that has gone a short path and, at this initial phase, this discipline defined itself and has created both conceptual and technical standards. Three archaeologists, three excavations and three dates can be considered the milestones of the conceptual evolution that has taken us to the present situation where the epistemology of the discipline seems to have been established with an acceptable level of definition: Nino Lamboglia with his work on the Albenga site in 1950; George Bass in Yassi Ada from 1961 and André Tchernia with the excavation of La Madrague de Giens from 1972.

\section{KEYWORDS}

UNDERWATER ARCHAEOLOGY, METHODOLOGY OF UNDERWATER ARCHAEOLOGY, ARCHAEOLOGICAL EXCAVATION, EVOLUTION OF UNDERWATER ARCHAEOLOGY 


\section{Introducción}

Piero Gianfrotta y Patrice Pomey definieron la arqueología subacuática como «una técnica particular al servicio de la arqueología; una técnica que permite a la arqueología extender su campo de investigación al amplio y rico mundo subacuático» (Gianfrotta y Pomey, 1980:10). Se alineaban así, en cuanto a la unidad de la arqueología terrestre y subacuática, con la opinión de George Bass resumida en la categórica afirmación de que «la arqueología subacuática debe ser llamada simplemente arqueología» (Bass, 1966), unidad indiscutible y mayoritariamente aceptada (Nieto, 1984). Sin embargo, entender la arqueología subacuática simplemente como una técnica conlleva el riesgo de caer en una visión restrictiva de una actividad que, en algunos casos, ha hecho nacer y, en otros, ha potenciado poderosamente nuevos campos y líneas de investigación y técnicas auxiliares e incluso nuevos planteamientos mentales en el investigador.

En el caso del yacimiento subacuático más típico, el barco hundido, el investigador se encuentra frente a un conjunto de materiales arqueológicos que contienen, en cuanto documento histórico, una información potencial no alterada ni por la venta al detal del comercio minorista, ni por el posterior consumo, a diferencia de lo que ocurre en un yacimiento de hábitat. Es, por lo tanto, un documento reflejo de la situación histórica tanto en el centro de producción como, especialmente, en el puerto o puertos de embarque de materiales a lo largo de la ruta seguida por el barco. Aquí reside una diferencia esencial de planteamiento entre la investigación de un yacimiento subacuático tipo barco y un yacimiento de consumo en tierra. Además, no se puede olvidar que un pecio es la consecuencia de un accidente, que puede producirse en cualquier punto de la ruta; por lo tanto, lo habitual es que un pecio no guarde una relación histórica con el yacimiento arqueológico terrestre más próximo ni incluso con la zona geográfica amplia en torno al lugar del naufragio.

Además, un pecio es la consecuencia de un acto fallido de voluntad humana que se produce, en términos arqueológicos, en un brevísimo lapsus de tiempo, el transcurrido entre la estiba de la nave para su último viaje y su naufragio. No solo es el reflejo de una decisión tomada en función de la oferta existente en el puerto de origen y de la demanda prevista en el puerto de destino no alcanzado por la nave; la decisión sobre la partida de una embarcación se toma, también, en función de un intrincado cúmulo de condicionantes: la existencia de una carga de retorno que haga más rentable el viaje, la idoneidad de la arquitectura del barco para la carga que debe transportarse y para la ruta que debe seguir, la existencia de una red de corresponsales del comerciante en otros puertos; en suma, de la compleja organización del comercio marítimo en cada momento (recuérdese la existencia de la Casa de Contratación en Sevilla y Cádiz o de la Plaza de las Corporaciones en Ostia, para momentos anteriores), etc. Cabe recordar aquí, a modo de ejemplo y como prueba de estos condicionantes, la carta comercial sobre una lámina de plomo encontrada en Empúries y fechada en el siglo vi aC (Sanmartí 
y Santiago, 1988) y en la que un comerciante marsellés encarga a su corresponsal en Empúries que entre en contacto con un posible comprador en Saigante (¿Sagunto?) para llegar a un acuerdo sobre el reparto de beneficios tras la venta del cargamento de una nave. Solo tras llegar a este acuerdo zarpará la nave desde Marsella. Este no es un hecho aislado; una carta similar hallada en Pech Maho (Lejeune et al., 1988), y de una datación muy próxima, nos obliga a desterrar como habitual, ya desde épocas tan antiguas, la imagen del navegante aventurero que va de puerto en puerto vendiendo lo que puede y comprando lo que encuentra, arriesgando su barco, su dinero y su vida. Cabe recordar también el absurdo morfológico de un ánfora para su uso en tierra, no solo porque la relación entre el peso de la arcilla, sin ningún valor comercial, y el del contenido llega a ser de 1:1 en las Dressel 1, sino también porque su forma impide que el objeto se mantenga en equilibrio. La pervivencia durante siglos de este objeto solo es explicable por su enorme idoneidad para su transporte en barco, en el que la morfología del ánfora permite su apilamiento en varias capas que, aparte de producir un sensible ahorro de espacio y, por lo tanto, un mayor beneficio económico en cada viaje, crea un bloque unitario de la carga que impide su desplazamiento, incluso en caso de temporal, que produciría el vuelco de la embarcación. Esta necesidad técnica de la estiba va a condicionar la organización del comercio ante la imposibilidad, o al menos dificultad, de hacer descargas parciales en los diversos puertos de una ruta. Es este, a modo de ejemplo, uno de los condicionantes técnicos que impone el transporte naval, ya que va a influir poderosamente en la organización del comercio marítimo en barcos de ruta directa entre puertos principales y barcos de redistribución entre puertos secundarios (Nieto, 1997) y que nos permitirá encontrar información, por ejemplo, sobre cuántas operaciones de compraventa se llevaron a cabo entre el productor y el consumidor final o por qué en un lugar de consumo se hallan unos objetos y no otros, o sobre la ruta seguida por la embarcación.

Dado el predominio de los pecios como objetivo de los trabajos de arqueología subacuática, y dada la preponderancia del uso del barco para el desplazamiento de mercancías a media y larga distancia, desde la Antigüedad, casi nos atreveríamos a denominar la arqueología subacuática como arqueología del transporte, en tanto que nos aporta informaciones complementarias para conocer, en toda su complejidad, las etapas básicas de una operación comercial: producción, transporte y consumo. Sobre todas ellas debe interrogarse un investigador ante un objeto arqueológico, ya que todas condicionan las conclusiones históricas que se obtengan.

No osaré complicar más el panorama proponiendo nuevos nombres para un campo de investigación que ya tiene muchos: arqueología submarina, arqueología subacuática, arqueología náutica, arqueología marítima, solo entre los coetáneos, todos ellos correctos, con más puntos de contacto que de diferencia y que probablemente son una prueba más de la evolución conceptual que ha experimentado esta especialidad arqueológica durante las últimas décadas. 


\section{Curiosidad, tesoro, arqueología}

El mar, por sus características de espacio geográfico inhóspito y misterioso, siempre ha ejercido una fascinación sobre el ser humano y como consecuencia una romántica atracción por explorarlo y conocerlo. Es en esta curiosidad por saber, que es el punto de partida de cualquier ciencia, en donde situamos también el origen de la arqueología subacuática.

Si a esta curiosidad unimos que el fondo del mar ha permanecido prácticamente inaccesible hasta los inicios del siglo xx, permitiendo la acumulación de objetos fabricados por el hombre desde la Prehistoria, es lógico y comprensible que el hombre se haya sentido atraído permanentemente por la recuperación de los «tesoros» submarinos.

Pronto, en menor o mayor grado, se reguló la actividad de los urinatores (fig. 1) y la Lex Rhodia ya estableció la remuneración que debían recibir estos primeros submarinistas a pulmón libre en función de la profundidad a la que se realizaban las recuperaciones. En esencia, se trata de una actividad que tiene como objetivo último la obtención de un beneficio económico por la recuperación de objetos valiosos del fondo del mar. Esta finalidad última ha permanecido inmutable hasta nuestros días; baste recordar únicamente los casos más recientes y conocidos: el expolio de la fragata Nuestra Señora de la Mercedes en España o el intento de recuperación del oro y la plata del galeón San José, en Colombia. Han cambiado las técnicas y los medios, y de la utilización de una piedra y una cuerda, tal como nos relata Plinio, se ha pasado a los vehículos submarinos de control remoto y a los

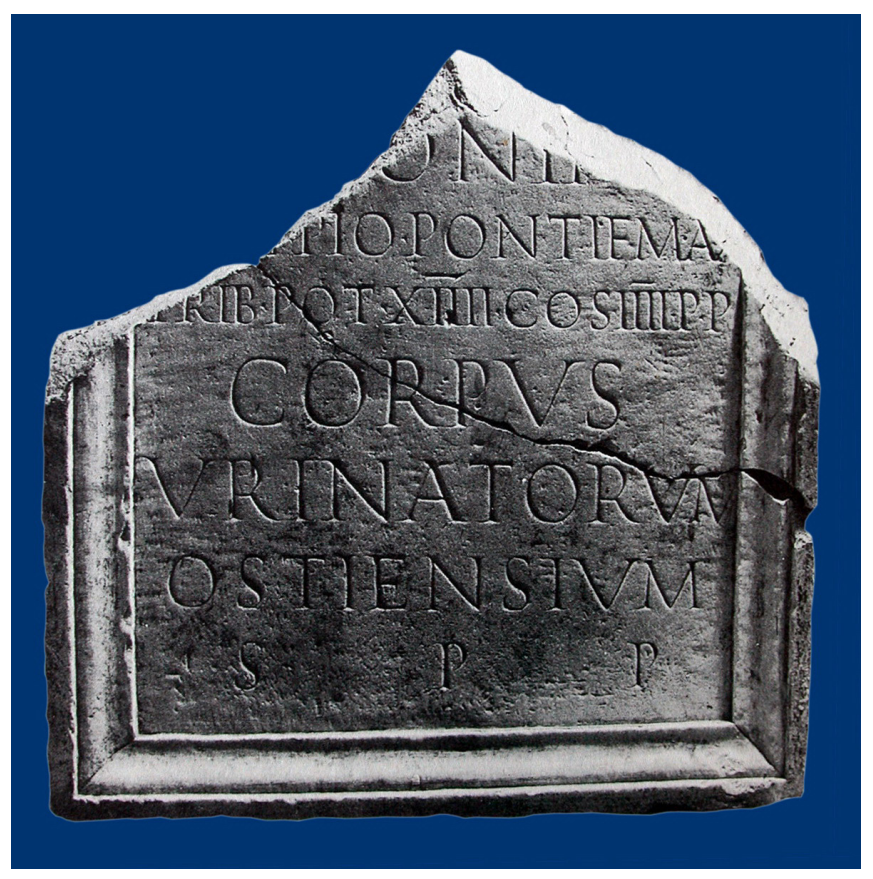

Figura 1. Inscripción dedicada al emperador Antonino Pio por los buceadores (urinatores) del puerto de Ostia. 
sonares de barrido lateral, pero la finalidad última sigue siendo la obtención de un beneficio económico. Curiosamente, en muchos ámbitos, se sigue llamando a esto arqueología y, a sus actores, arqueólogos.

\section{La protoarqueología subacuática}

Es obvio que las condiciones de un trabajo que debe desarrollarse bajo el agua, en un medio desfavorable para el ser humano, evolucionan al unísono que lo hacen los medios técnicos que facilitan esta actividad. No es, por lo tanto, extraño que a partir de los años cincuenta del siglo xx, superados los avatares de la II Guerra Mundial, se popularizara un invento militar materializado en 1942 por el comandante Cousteau y el ingeniero Gagnan: el regulador de presión variable. Este artilugio liberó a los submarinistas de los pesados equipos de buzo con suministro de aire desde la superficie, que no permitían nadar sino caminar bajo las aguas. El buceo autónomo permite «volar» bajo las aguas con un equipo ligero y abre esta actividad a un número ilimitado de personas, entre ellas los arqueólogos.

Difícilmente puede aplicarse una correcta metodología de excavación con un equipo de buzo clásico (fig. 2) por lo que las actuaciones realizadas con este equipo, aun reuniendo muchos de los requisitos de un trabajo arqueológico en cuanto al planteamiento, los

Figura 2. La evolución de la arqueología subacuática científica está íntimamente condicionada por los medios técnicos disponibles para trabajar bajo el agua.

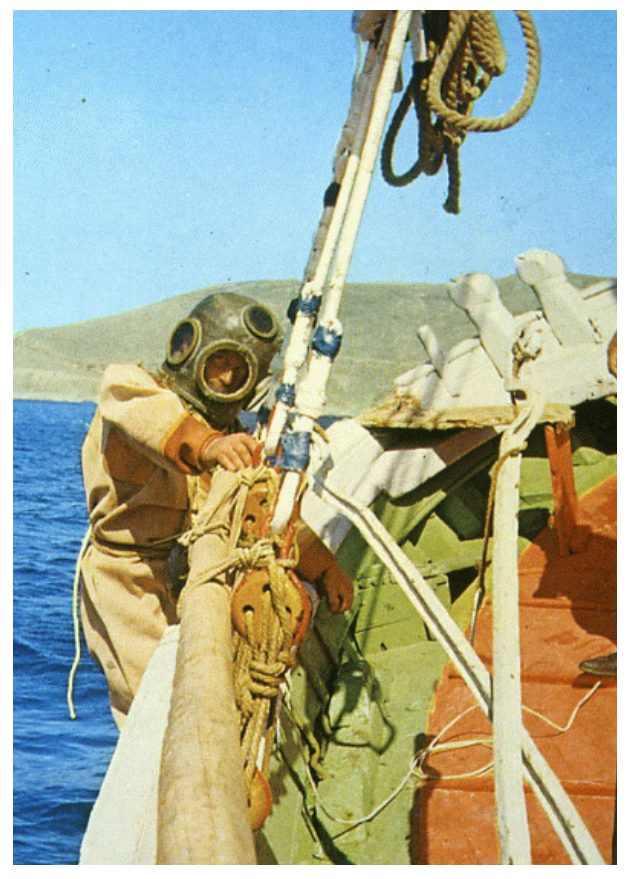


objetivos y la postexcavación, se encuentran más próximos a una recuperación que a una excavación arqueológica.

Varios ejemplos nos sirven para documentar este período: Antikytera, Mahdia y, por ser más próximo a nosotros, Cala Cativa en la provincia de Girona. Los tres yacimientos fueron descubiertos por buzos clásicos que efectuaban trabajos de recolección de esponjas, y los tres fueron excavados con equipos de buzo clásico y en los tres, tras el descubrimiento, hubo un control del proyecto, desde la superficie, por parte de arqueólogos; en los tres, el material recuperado fue total o parcialmente depositado en un museo público, y fue objeto de estudio y publicación.

En 1894 unos buzos griegos que se dedicaban a la pesca de esponjas en la zona del cabo de Creus (Girona) localizaron en Cala Cativa (Port de la Selva) un barco romano con un cargamento de ánforas Pascual 1. La noticia llegó a conocimiento de D. Romualdo Alfarás, que era corresponsal de la Asociación Artístico-Arqueológica Barcelonesa, y contrató a los buzos para que efectuaran la extracción de las ánforas. Alfarás era, para la época, un arqueólogo y, además, con una responsabilidad sobre el patrimonio cultural en tanto que corresponsal de la asociación a la que pertenecía. El producto de la recuperación, 43 ánforas enteras y fragmentos de otras 19, fue depositado en una institución cultural y, actualmente, una parte se conserva en Barcelona en el Museu d'Arqueologia de Catalunya. La actividad se realizó con una finalidad de investigación histórica y la prueba es que el mismo Alfarás publicó en el boletín de la asociación en 1894 lo que sin duda es, para la época, una memoria de excavación (Raurich, 1994).

A efectos de la finalidad de este artículo conviene prestar atención a dos detalles: uno, el título del artículo que publica Alfarás, "Pesca de ánforas», y el otro, que al año siguiente se efectuó una nueva extracción de ánforas, que no cogió desprevenida la maquinaria del Estado, ya que los objetos fueron subastados, según consta en un edicto de la Ayudantía de Marina de Cadaqués. Estas ánforas eran restos de un naufragio de propietario desconocido y, por lo tanto, en cumplimiento de la legislación vigente en el momento y que perduró hasta bien entrado el siglo xx, el beneficio debía ser repartido entre el hallador y el Estado.

Probablemente, tanto el barco de Antikythera como el de Mahdia se hundieron a finales del siglo I aC, cuando transportaban un ingente y espectacular cargamento de obras de arte griegas procedentes quizá del expolio de Atenas por los romanos. La recuperación de estos cargamentos se inició en el año 1900 por iniciativa y bajo el control de las autoridades de cultura griegas y, en 1907 en Mahdia, bajo el control del arqueólogo A. Merlin (Merlin y Poinssot, 1930); actualmente las piezas recuperadas ocupan varias salas en el Museo Arqueológico Nacional, en Atenas, y en el Museo Nacional del Bardo, en Túnez.

Si bien el hallazgo de Cala Cativa pasó desapercibido, incluso para el mundo académico, los espectaculares hallazgos de Antikythera (fig. 3) y Mahdia contribuyeron poderosamente a cimentar una imagen fantástica de los «tesoros» submarinos y ayudaron a acuñar la designación del Mediterráneo como «el mayor museo de arqueología del mundo». 


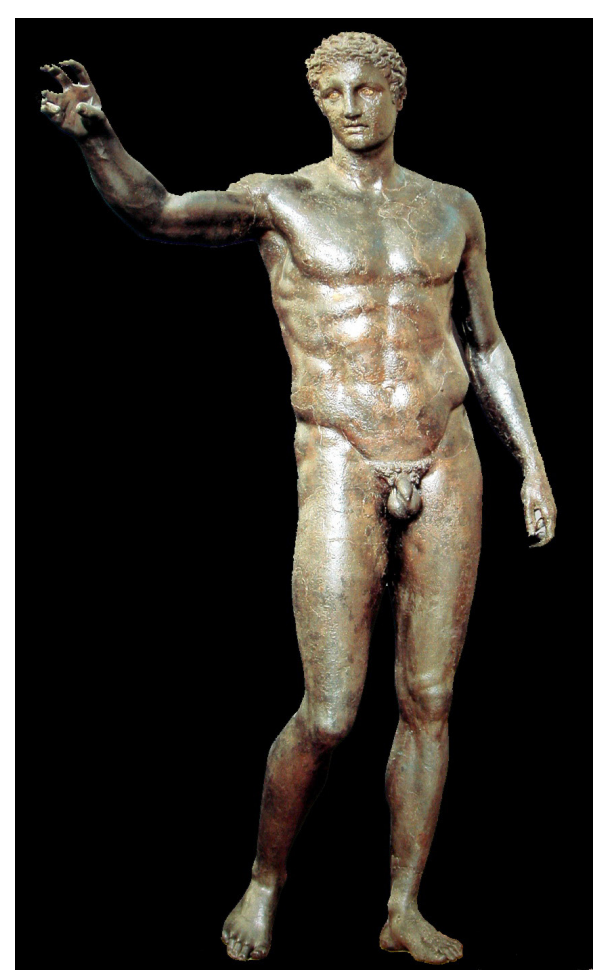

Figura 3. Estatua procedente del pecio de Antikytera (foto del autor).

\section{Hacia la arqueología subacuática científica}

\section{Primera etapa (Nino Lamboglia. El pecio como documento histórico)}

Nino Lamboglia fue, en la primera mitad del siglo xx, uno de los artífices de la sistematización de las cerámicas de mesa de época romana, a partir especialmente de sus excavaciones en el yacimiento de Albintimilium (Lamboglia, 1950), en donde llevaba años afinando la cronología de las formas cerámicas a partir de excavaciones estratigráficas y de las valiosas informaciones que aportan las tumbas, como conjuntos cerrados. En el mismo año de la publicación de la monografía de Albintimilium se descubrió en Albenga una nave romana con un cargamento mayoritariamente de ánforas Dressel 1. Siendo un pecio el conjunto cerrado por antonomasia, no es extraño y es comprensible que el profesor se planteara y llevara a cabo ese mismo año, a partir del 8 de febrero, la recuperación de objetos arqueológicos de ese yacimiento, utilizando tanto buzos clásicos como buceadores autónomos, gracias al equipo inventado ocho años antes por Cousteau y, a partir del 13 de febrero, lo 


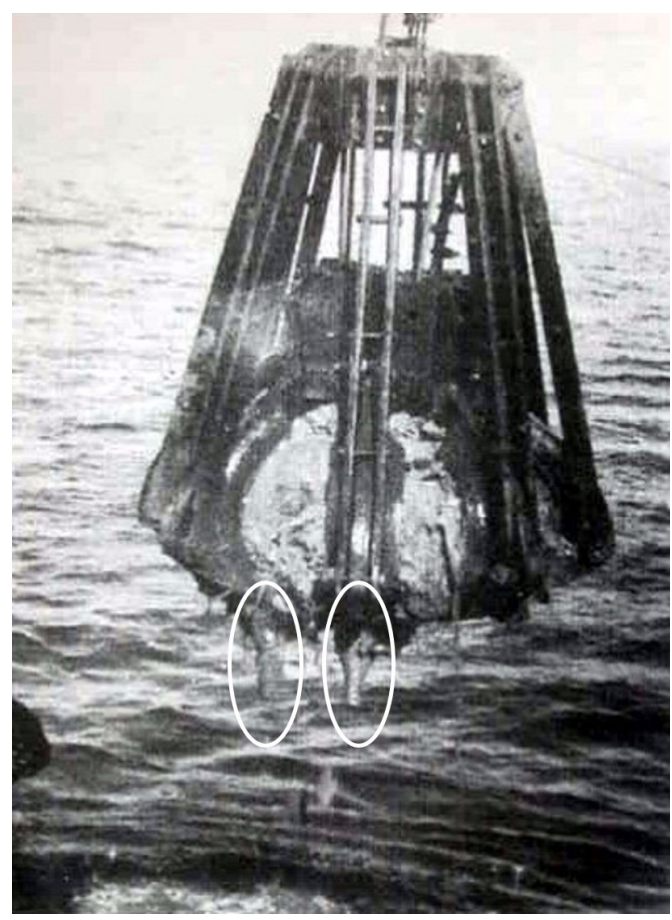

Figura 4. Draga del Artiglio utilizada por Lamboglia en 1950 para recuperar el cargamento del pecio de Albenga. Obsérvese en la parte inferior de la draga, marcados con óvalos, el tercio inferior de dos ánforas Dressel 1 (imagen en Lamboglia, 1952, fig. 8).

que es más significativo, en tanto que ilustra la mentalidad del momento y el objetivo de la operación, una inmensa draga, el Artiglio, capaz de extraer, en cada operación de su cuchara, miles de objetos arqueológicos con la consiguiente destrucción tanto de buena parte de los objetos como del yacimiento (fig. 4). Éticamente aterrado ante esta destrucción, Lamboglia interrumpió estos trabajos el 21 de febrero.

Nino Lamboglia, refiriéndose a la que algunos consideran la primera excavación arqueológica subacuática, la actuación realizada en 1950 en el pecio de Albenga, reconocía, con una sinceridad que le honra, los graves errores cometidos al utilizar una draga para extraer material arqueológico del fondo del mar, y confesaba: «El cementerio de ánforas provocado por la draga a bordo del barco habría turbado la conciencia de cualquier arqueólogo y turbó también la nuestra», reafirmando una idea ya expresada públicamente en 1958 en el acto inaugural del II Congreso Internacional de Arqueología Submarina: «Deseamos ser cautos y saber esperar para ver cómo se orientan los métodos de trabajo y cómo se presenta la posibilidad de organizar una auténtica excavación arqueológica submarina y no una recuperación de objetos del fondo del mar con fines más o menos científicos: así creo que podemos llamar a la mayor parte de la investigación realizada hasta el momento en el fondo del mar" (Lamboglia, 1961a: 13).

Si tuviéramos que encontrar una fecha para el inicio de la arqueología subacuática como actividad científica, nos inclinaríamos por aquel 21 de febrero de 1950 en que 
Figura 5. Pecio de Punta Scaletta. Campana batiscópica utilizada por Lamboglia para poder dirigir, desde debajo del agua, el trabajo de los buceadores (imagen en Gianfrotta y Pomey, 1981, pág. 79).

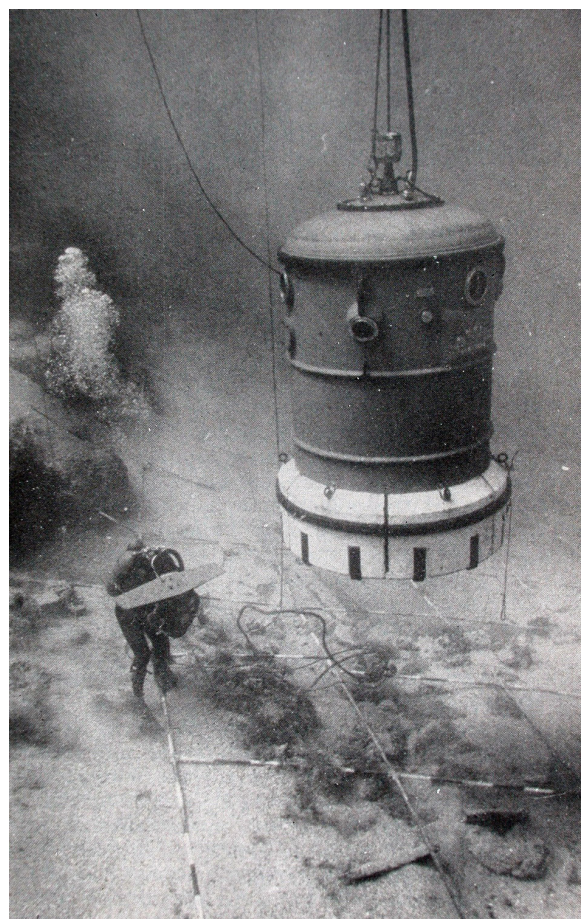

Lamboglia decidió interrumpir los trabajos en Albenga al entender un pecio, no como una «cantera» de objetos arqueológicos, sino como un documento histórico que debía excavarse con la misma metodología, rigor y ética que un yacimiento terrestre.

Seguirían en los años posteriores nuevas campañas para adaptar la metodología arqueológica al ámbito submarino y para encontrar unos medios técnicos idóneos, acorde, todo ello, con la deontología arqueológica. Ya en Spargi, en 1958, se cuadriculó el yacimiento para documentar los hallazgos con la ayuda de la fotografía, incluso Lamboglia se sumergía en una campana batiscópica para supervisar, ahora bajo el agua, los trabajos (fig. 5). Por primera vez se realizó el plano de un pecio (Lamboglia, 1961b); años más tarde el profesor volvería a Albenga (Lamboglia, 1964), ahora con una metodología equiparable a la utilizada en tierra en esa época.

Desgraciadamente un accidente automovilístico en 1977 truncó la vida de uno de los más lúcidos y competentes arqueólogos del siglo xx y la evolución de su concepto de arqueología subacuática se vio interrumpida, pero ya había legado los congresos internacionales de arqueología submarina, de los que se celebraron seis entre 1955 y 1982. Había creado en 1957 el Centro Sperimentale di Archeologia Sottomarina y una publicación periódica especializada, Forma Maris Antiqui, con todo lo cual la arqueología subacuática comenzó a tener una sólida presencia en el mundo académico y le hizo merecedor, por la calidad y cantidad de sus aportaciones, del título de «padre» de la arqueología subacuática. 


\section{Segunda etapa (George Bass. El pecio como documento histórico unitario)}

En 1960 la Universidad de Pensilvania envió a Turquía a un joven profesor, George Bass, con el encargo de localizar un yacimiento arqueológico que pudiera convertirse en campo de investigación y de prácticas para sus alumnos. A su llegada fue recibido por Peter Throckmorton, un fotoperiodista bregado como corresponsal en varias guerras y al que los pescadores de la zona de Bodrum habían enseñado varios pecios, haciendo nacer su afición por la arqueología subacuática. Casualmente coincidió en la antigua Halikarnaso con Honor Frost, en uno de sus desplazamientos para continuar sus estudios sobre los puertos y las anclas antiguas en el Mediterráneo oriental. Ese mismo año comenzaron la excavación del pecio de cabo Gelidonya, uniéndose al equipo un submarinista que había formado parte del equipo de Cousteau y que participó, desde 1952, en la excavación del Grand Gogloué y que, sin duda, aportó la experiencia en este tipo de trabajos e información sobre algunas soluciones técnicas, entre ellas y como más significativa la manga de succión por aire, el aspirador para eliminar sedimentos ya utilizado profusamente por Cousteau y Lamboglia.

Cabo Gelidonya debió ser el campo de pruebas, el ensayo general, que permitió a George Bass volver a Pensilvania, convencer a su universidad y enseñar a hacer inmersión subacuática a un primer grupo de estudiantes de arqueología. Con ellos, en 1961, volvió a Turquía e inició sus campañas en Yassi Ada, en donde entre 1961 y 1969 trabajaría en dos pecios, una nave bizantina del siglo VII (Bass y Van Doorninck, 1982) y otra romana del siglo iv dC. Hay en esto un cambio de enorme trascendencia; por primera vez una excavación arqueológica subacuática sería dirigida y ejecutada por arqueólogos que tenían contacto directo con el yacimiento y que trasladarían al fondo del mar las buenas prácticas y la metodología arqueológica, ya que, como confesó el propio Bass (1966): "he llegado a la conclusión de que el mejor excavando no es necesariamente el mejor haciendo inmersión".

Fue probablemente el hecho de que unos arqueólogos se enfrentaran personalmente a la problemática de aplicar bajo el agua una correcta metodología arqueológica lo que permitió inventar las soluciones técnicas que lo hicieran posible. En la fase de extracción de sedimentos, se perfeccionaron las mangas de succión haciéndolas más sencillas, ligeras y manejables, lo cual permitió trabajos más meticulosos y respetuosos con el conjunto y con los objetos. En la fase de documentación, se cuadriculó el yacimiento con una estructura metálica que posibilitaba posicionar los objetos y captar fotográficamente cada cuadro excavado, siempre desde la misma distancia, con el fin de obtener un mosaico fotográfico. Consciente de las limitaciones de esta técnica, en cuanto a la precisión de los resultados, Bass incorporó a su equipo a D. Rebikoff que, en 1958, en el II Congreso Internacional de Arqueología Subacuática, había presentado una comunicación con el elocuente título "Restitution photographique stéréoscopique des épaves immergées» (Rebikoff, 1961); ya en 1963 Bass utilizó, en Yassi I, una barra flotante por la que se deslizaba una máquina fotográfica, sistema que modificó sustancialmente al año siguiente, en Yassi Ada II, utili- 
Figura 6. Dibujo del desarrollo de los trabajos en el pecio de Yassi Ada durante los primeros años de excavación (imagen en Bass, 1972, pág.151).

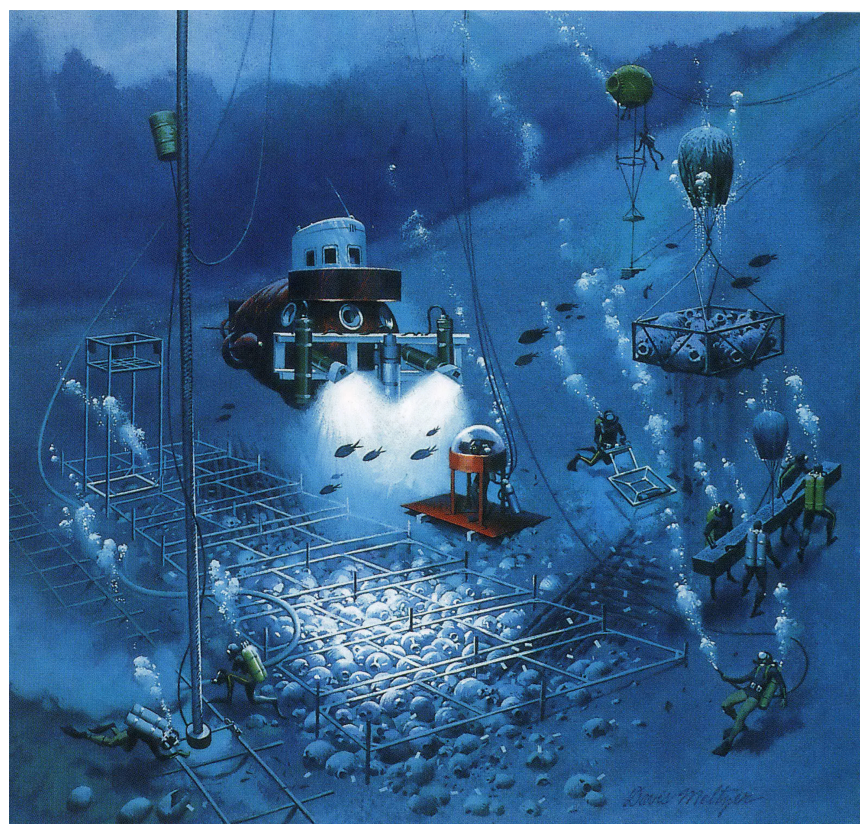

zando un minisubmarino en cuya proa se colocaron dos máquinas fotográficas, imitando los aviones que se venían utilizando en cartografía aérea. Se habían dado los primeros pasos hacia la fotogrametría que serían perfeccionados por Tchernia entre 1972 y 1982 en la excavación de la Madrague de Giens y que, hoy en día, es una técnica imprescindible en cualquier excavación arqueológica subacuática.

George Bass es un comunicador nato y los espectaculares artilugios inventados o adaptados para facilitar el trabajo subacuático, como el minisubmarino Asherah, la cabina telefónica submarina o una llamativa esfera metálica pintada de amarillo y utilizada como cámara de descompresión subacuática, aparecieron en espectaculares dibujos (fig. 6) y fotografías a color en libros y revistas, especialmente en National Geographic, causando la admiración y la envidia de arqueólogos y submarinistas.

Es lo que esperaba encontrar durante mi estancia en Yassi Ada y que no encontré, pero si localicé, entre hierbajos, en un patio del museo de Bodrum. Lo que sí encontré bajo el agua fue un simple tubo de plástico utilizado como manga de succión, unas máquinas fotográficas y plaquetas y cintas métricas para dibujo. Preguntado por esto, Bass vino a contestar que bastantes problemas le daba el mar como para invertir energías, tiempo y dinero en artilugios que lo distrajesen del fin último que era la investigación histórica. Bass, al final de su estancia en Yassi Ada, llegó a la depuración de la aplicación de la metodología arqueológica al fondo de las aguas; había aislado la quintaesencia y había desmontado el mito de que una excavación arqueológica subacuática, a una profundidad accesible al ser humano, requiere imprescindiblemente complejos y carísimos medios técnicos. 

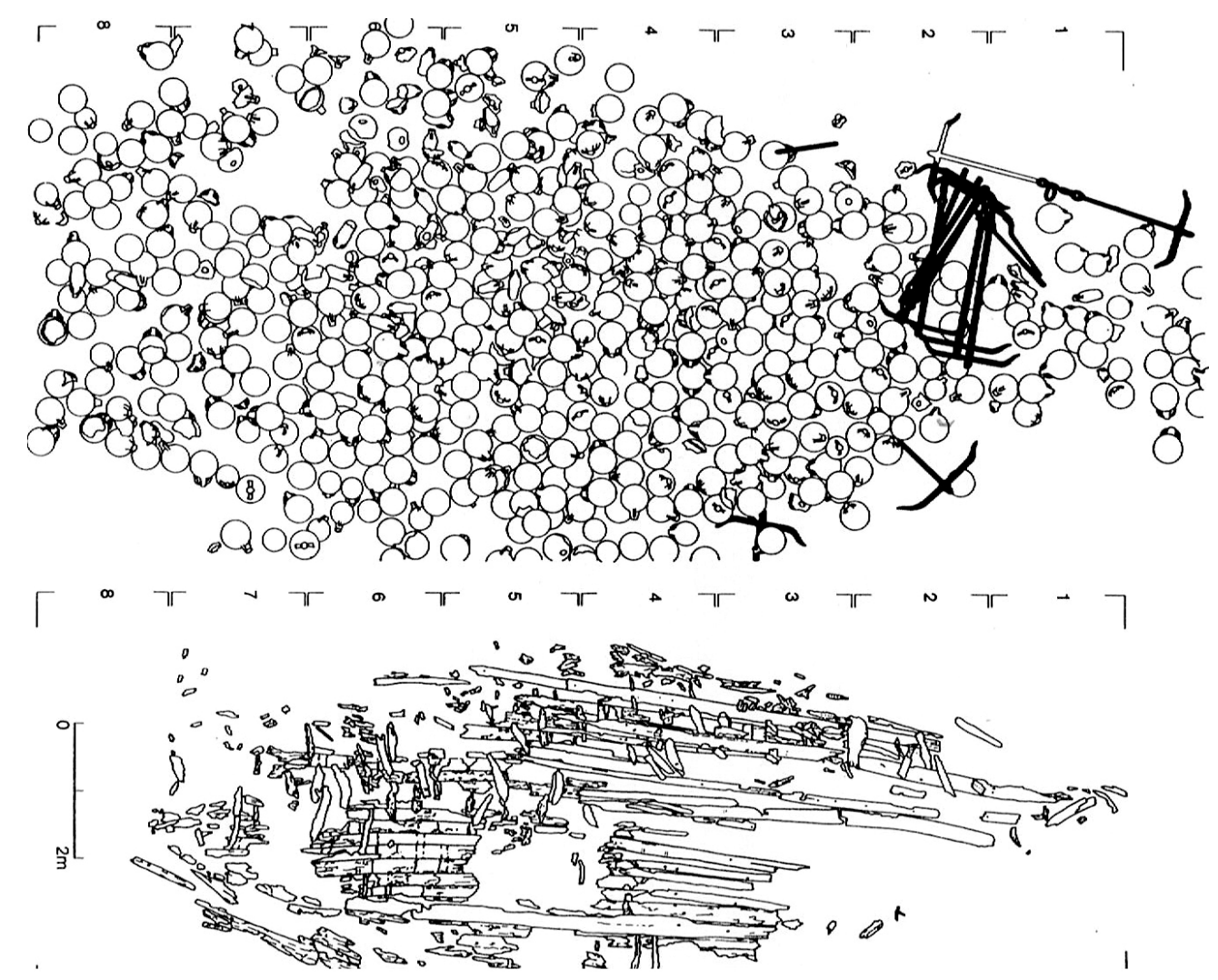

Figura 7. Yassi Ada I fue el primer pecio excavado en su integridad como un documento unitario formado por el cargamento y el casco de la embarcación (planos en Bass y van Doorninck, 1982).

Bass estableció un modo de hacer una excavación arqueológica bajo el agua de manera sencilla y asequible y nos dotó de unos medios técnicos para hacerlo, que con escasas variaciones siguen siendo utilizados hoy en día.

Con estos medios y este planteamiento, Bass excavó el pecio de Yassi Ada I; fue la primera vez que un pecio se excavaba en su totalidad: la primera vez que un documento histórico de este tipo podía conocerse en su integridad y ser analizado como documento unitario consecuencia de un acto concreto de la voluntad humana. Es bajo este planteamiento que encuentra explicación el símil del pecio con una fotografía, en tanto que ambos reflejan un instante concreto de la historia, pero con todos sus detalles.

Esta visión unitaria del cargamento se extendió también al casco de la embarcación y, gracias a los trabajos de Frederich H. Van Doorninck, pudimos disponer por primera vez de la planimetría completa y de un estudio preliminar, realizado bajo el agua, de un barco antiguo. Se ampliaban de este modo las posibilidades de investigación sobre arquitectura 
naval antigua y se establecía una relación biunívoca entre el cargamento de una nave y su idoneidad arquitectónica para el transporte de esas mercancías.

Es probablemente esta concepción unitaria de un pecio, formado tanto por la totalidad del cargamento como por el casco de la embarcación, una aportación esencial de los trabajos de George Bass (fig. 7).

En 1972 fundó en Filadelfia el American Institute of Nautical Archaeology (AINA) que, tras la incorporación de Bass a la Universidad de Texas, pasó a denominarse simplemente INA y extendió su campo de actuación a todo el mundo.

\section{Tercera etapa}

\section{(André Tchernia. El pecio como documento unitario, reflejo de la realidad histórica en tierra firme)}

La excavación del Grand Congloué realizada entre 1952 y 1957, bajo la supervisión científica de Fernand Benoit, no fue un hecho aislado en Francia, tuvo una continuidad en otros yacimientos y con otros actores. Fue una semilla que germinó de manera explosiva a partir del 14 de octubre de 1966 con una resolución publicada en el Journal officiel por la que se creaba la Direction des Recherches Archéologiques Sous-marines (DRASM). Inmediatamente, el primero de febrero del año siguiente, André Tchernia fue nombrado primer director de la institución y poco después, en el mes de agosto, se botaba el Archéonaute, el primer barco diseñado y construido para hacer arqueología submarina. Todo ello es una prueba evidente de la implicación decidida del gobierno de un país, por primera vez, para actuar sobre el patrimonio cultural subacuático.

La presencia de Tchernia al frente de la DRASM fue corta, hasta septiembre de 1968, pero suficiente para hacer, en el pecio Planier 3, como Bass había hecho en Gelidonya, un ensayo general que le permitiría en 1972 iniciar la excavación de la Madrague de Giens (Tchernia et al., 1978).

Tchernia y Bass no se conocieron personalmente hasta un momento muy tardío, en 1982, con motivo de la celebración en Bodrum de uno de los Cursos Intensivos Europeos sobre Arqueología Subacuática ${ }^{1}$ organizados por el Consejo de Europa, pero me consta personalmente la influencia del americano sobre Tchernia en cuanto a la concepción de la arqueología subacuática. Él mismo dejó constancia en una publicación cuando, al citar

1. Estos cursos tuvieron una gran trascendencia, ya que en ellos se formó una nueva generación de arqueólogos que, en las últimas décadas, hemos ocupado puestos de responsabilidad en esta materia en el Mediterráneo y que heredamos una concepción de la arqueología subacuática que procede de las experiencias de Lamboglia, Bass y Tchernia. Recuerdo a Jean-Yves Empereur, que trabaja en la bahía de Alejandría y especialmente en la investigación del antiguo faro de la ciudad; Francisco Alves, que fue el creador y durante varias décadas director del Centro Nacional de Arqueologia Náutica e Subaquática de Portugal; Hélène Bernad y Marie Pierre Jezegou, que todavía hoy son arqueólogas de la DRASSM; Aglaia Archontidou, durante años responsable de la Aforia de Antigüedades Subacuáticas en Grecia y yo mismo. 
explícitamente el libro de Bass Archaeology under water, ${ }^{2}$ afirma: «participamos de esa filosofía y la acentuamos más» (L'Hour, 2012: 39).

Tchernia, especialista en tráfico y comercio marítimo, a partir de un profundo conocimiento de las ánforas, asume el concepto de documento histórico procedente de Lamboglia y el de documento unitario de Bass y avanza al concebir ese documento histórico unitario como un reflejo, una consecuencia, de la realidad histórica en tierra firme, llevando a la práctica este pensamiento. Acabada la excavación de la Madrague de Giens, parte de su equipo se trasladó al Lacio (Hesnard, 2011) para estudiar el centro de producción de donde procedían las ánforas Dressel 1B halladas en el pecio.

Con Tchernia, que conocía las ánforas Dressel lB en los lugares de consumo y que venía de estudiar su transporte en un barco y que posteriormente estudió su centro de producción, se acabaron las bizantinas discusiones entre arqueología terrestre y arqueología subacuática para pasar a hablar simplemente de arqueología.

El equipo de la Madrague, André Tchernia, Patrice Pomey y Antoinette Hesnard, perfeccionó la fotogrametría para documentar la excavación. Aplicó la incipiente informática a los trabajos de inventario y, con Pomey, los estudios de arquitectura naval experimentaron un notable desarrollo. El barco, el más grande estudiado hasta el momento en el Mediterráneo, se excavó prácticamente en su totalidad, ${ }^{3}$ lo que hizo evidente una problemática que existe también en una excavación terrestre, pero que en un pecio se ve magnificada, cuando hay que desplazar, almacenar, conservar, estudiar y publicar miles de ánforas, la mayoría enteras (fig. 8), y muchos miles de otros objetos cerámicos, orgánicos y metálicos ${ }^{4}$ que requieren, todos ellos, como mínimo, un desalado.

Es con estos planteamientos que se desarrollan actualmente las excavaciones arqueológicas subacuáticas científicas, entre las que cabe destacar la del ballenero vasco hundi-

2. Este libro, aparentemente de divulgación ligera, traducido a varios idiomas, es altamente recomendable para cualquier estudiante de arqueología, ya que, aparte de hacer nacer vocaciones por la arqueología subacuática, resulta esencial para entender la evolución tecnológica y conceptual de la disciplina experimentada por George Bass y que nos ha llevado hasta hoy.

3. Los responsables de la excavación decidieron dejar intacta una pequeña parte del yacimiento como reserva para que en el futuro pudiera ser excavada con nuevas técnicas y nuevos planteamientos.

4. Este es un problema muy grave en la excavación de un pecio. Un barco de comercio es una máquina diseñada para transportar el mayor número posible de objetos en el menor espacio posible, por lo que la cantidad y las características del material arqueológico que produce una excavación de este tipo de yacimiento, cuando es de gran tamaño, desborda la logística habitual de la postexcavación. Cualquiera que haya visto un almacén de ánforas enteras se habrá percatado del espacio que ocupan y de la cantidad de metros cuadrados edificados que requieren. El medio submarino proporciona materiales empapados en agua salada que es necesario desalar para evitar las consecuencias nocivas de la cristalización de la sal. Probablemente la más genuina tipología de objetos que proporciona el medio subacuático es la de los materiales orgánicos, los cuales, para su conservación, sea mediante impregnación en polietilenglicol o por liofilización, requieren unas instalaciones muy específicas y en ocasiones complejas, especialmente si aquello que se quiere exhibir en un museo es el casco de una embarcación. Bass, tras el estudio de las ánforas, las acabó dejando en el fondo del mar y la DRASSM, últimamente, desbordados sus almacenes, ha optado por hacer almacenes visitables en el fondo del mar con las ánforas procedentes de excavaciones antiguas, especialmente las halladas en el Grand Congloué. Esta solución choca con reticencias filosóficas tanto entre los arqueólogos como entre la sociedad, pero también con inconvenientes legales en un ordenamiento jurídico que no contempla la problemática específica del patrimonio cultural subacuático. 


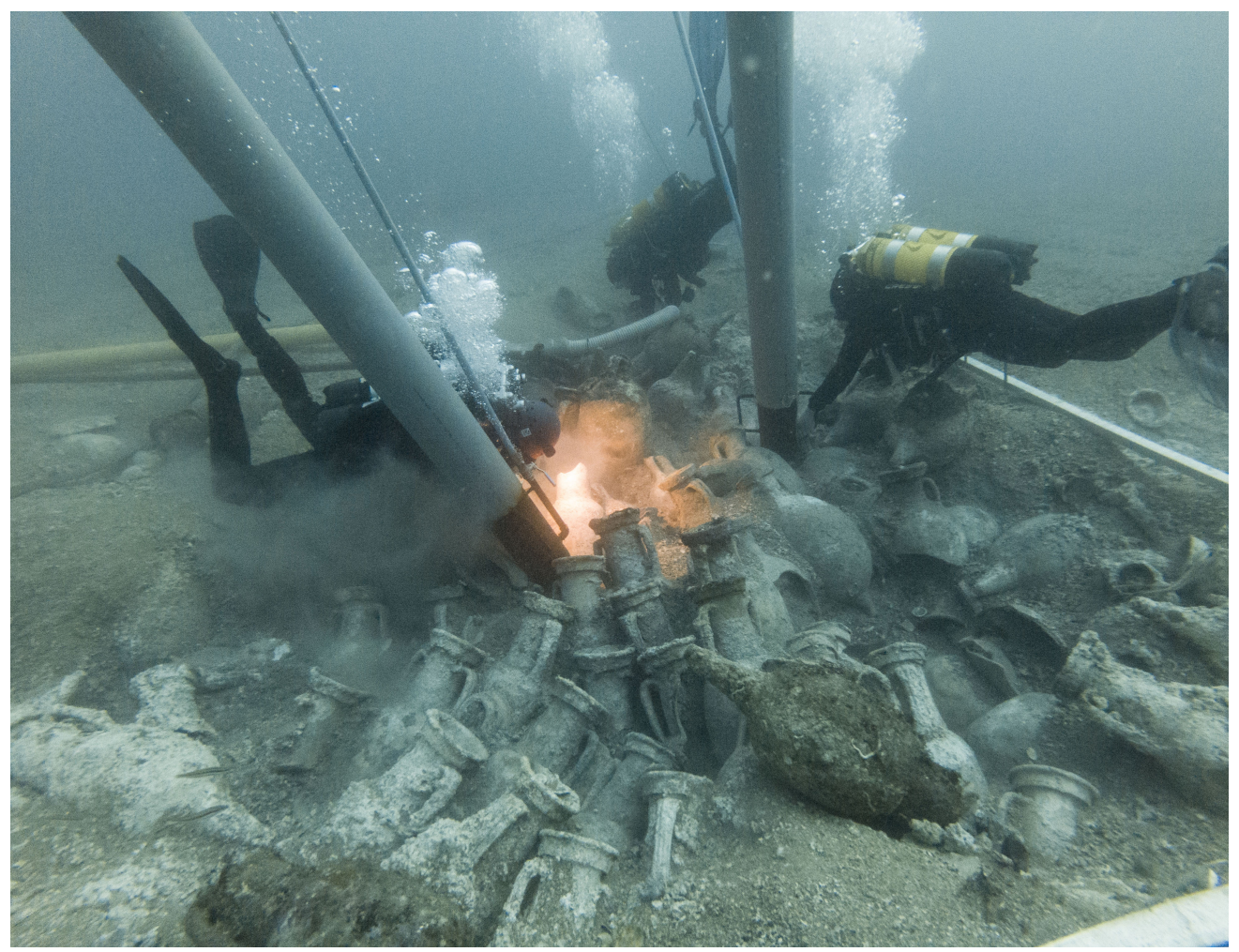

Figura 8. Un proyecto de excavación de un barco debe contemplar la logística necesaria para dar una respuesta satisfactoria a la problemática que genera el tratamiento de miles de objetos arqueológicos (Pecio Illes Formigues 2. [Palamós - Palafrugell, Girona] Foto: Archivo CASC).

do en 1565 en Red Bay (Canadá) y excavado entre 1978 y 1985 por el equipo de Parks Canada bajo la dirección de Robert Grenier y magníficamente publicado en 2007 (Grenier et al., 2007).

\section{La arqueología subacuática a finales del siglo xx}

El estándar técnico y conceptual creado por Lamboglia, Bass y Tchernia es el que hoy día sigue siendo referencia para evaluar la calidad de una excavación arqueológica (fig. 9). Siendo estrictos, hemos de reconocer que aquello para lo que Bass y Tchernia crearon un estándar fue para la fase de excavación de un barco hundido, que es solo una pequeña parte de un proceso arqueológico. 


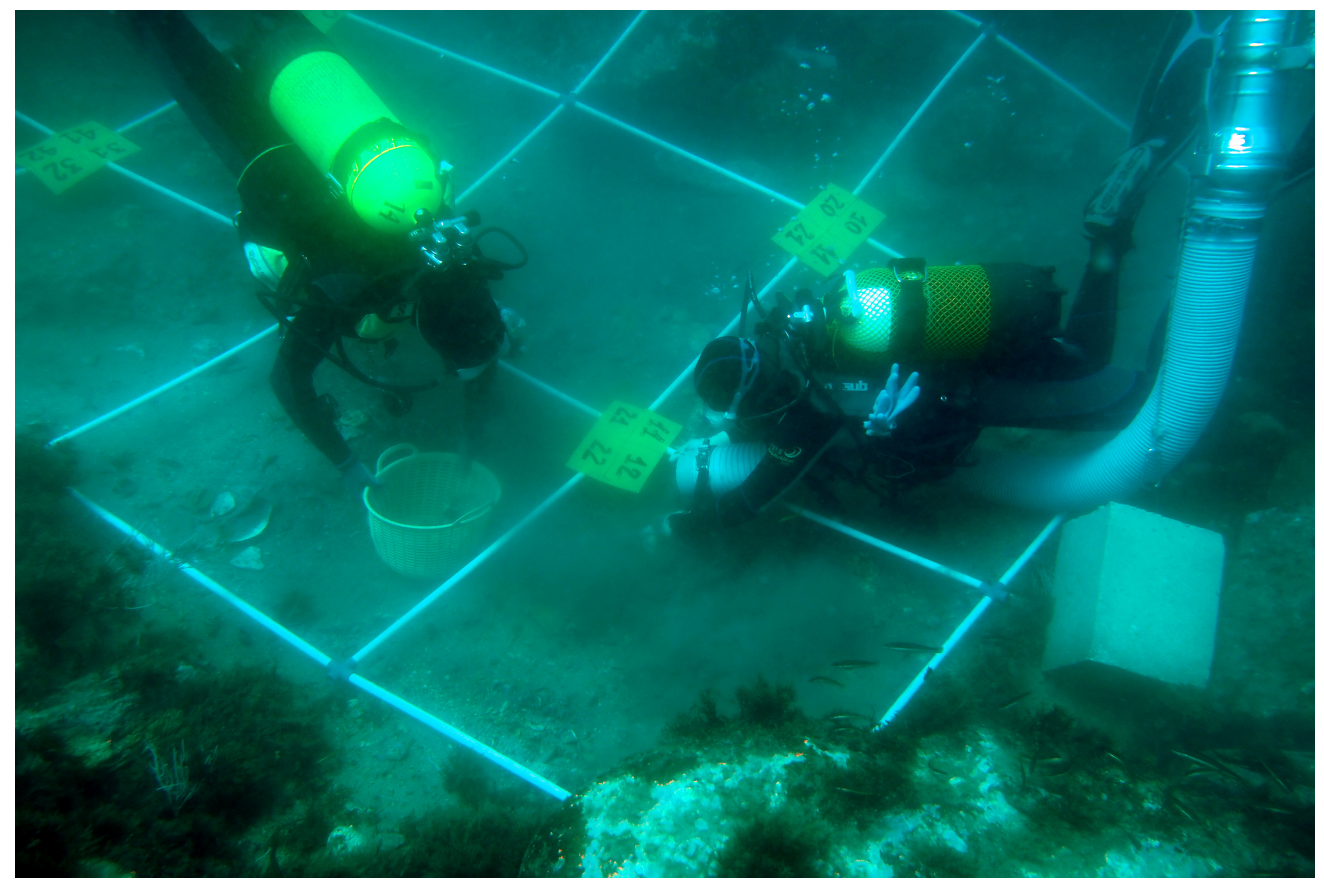

Figura 9. La arqueología subacuática actual ha traspasado al medio acuático los estándares metodológicos científicos de la arqueología (excavación efectuada por la Universidad de Cádiz en 2017 en el pecio La Ballenera. Algeciras - Cádiz. Foto del autor).

La aceptación generalizada del concepto de "patrimonio cultural subacuático» oficializado por la UNESCO, ${ }^{5}$ al dedicar a su protección su convención de 2001, conlleva la introducción de la sociedad como nuevo actor en el proceso arqueológico; una sociedad que tiene derecho a participar de los beneficios intelectuales que aporta una herencia cultural que le pertenece.

Este uso social obliga a la implementación de mecanismos de gestión que comienzan por la protección legal de ese patrimonio. Ya desde 1985, la Ley 16/1985 del Patrimonio Histórico Español estableció, al igual que las sucesivas normativas promulgadas por las comunidades autónomas, el mismo nivel de protección para los bienes arqueológico «tanto si se encuentran en la superficie o en el subsuelo, en el mar territorial o en la plataforma continental» (artículo 40.1). Este precepto legal se vio reforzado en el año 2005 con la ratificación por parte del Parlamento español de la Convención 2001 de la UNESCO, acto político por el que el articulado y el anexo de esa convención constituyen, desde su entrada en vigor el 2 de enero de 2009, parte de nuestro ordenamiento jurídico. En el artículo

5. «La primera vez que se utilizó de manera independiente el concepto jurídico de patrimonio cultural subacuático fue en la Recomendación 848, de 4 de octubre de 1978, relativa al patrimonio cultural subacuático, adoptada por la Asamblea Parlamentaria del Consejo de Europa» (Aznar, 2008). 
primero la Convención define: "Por "patrimonio cultural subacuático" se entiende todos los rastros de existencia humana que tengan un carácter cultural, histórico o arqueológico, que hayan estado bajo el agua, parcial o totalmente, de forma periódica o continua, por lo menos durante 100 años». ${ }^{6}$

Partiendo de la base de que una ley protege, pero que no se puede proteger aquello que se desconoce, y siendo conscientes de que el patrimonio arqueológico, en general, es un bien enormemente frágil, especialmente el subacuático por el tradicional abandono que ha sufrido, las cartas arqueológicas se convierten en una herramienta imprescindible para gestionar este patrimonio en tanto que, desde el conocimiento de la realidad, se pueden planificar las acciones más idóneas.

Si ya el artículo 4 de la Recomendación sobre la conservación de los bienes culturales que las ejecuciones de obras públicas puedan poner en peligro, promulgada por la UNESCO en 1968, avisaba sobre la necesidad de realizar inventarios de los bienes culturales y el mismo organismo reiteraba esta necesidad en 1972, en la llamada Carta de París, parece como si estas recomendaciones solo fueran aplicables a los bienes ubicados en tierra firme. Fue la Carta internacional para la protección y la gestión del patrimonio cultural subacuático adoptada por ICOMOS en Sofía, en 1966, y conocida como Carta de Sofía, la que extiende estas recomendaciones a los bienes culturales subacuáticos; esta última fue un documento inspirador de la Convención 2001 de la UNESCO y es por ello que en el artículo 22 se recomienda: «los Estados parte establecerán autoridades competentes o, en su caso, reforzarán las ya existentes para que puedan elaborar, mantener y actualizar un inventario del patrimonio cultural subacuático y garantizar eficazmente la protección, conservación, presentación y gestión del patrimonio cultural subacuático, así como la investigación y la educación».

La incorporación de España a los estándares extranjeros se produjo con retraso, en un momento en que el concepto de patrimonio cultural subacuático estaba extendiéndose y que vino a coincidir con la asunción, por parte de las comunidades autónomas, de las competencias en arqueología, lo que facilitó un auge de las intervenciones preventivas, de las actuaciones de urgencia, etc.; en suma, de la arqueología de gestión. Es en este contexto en que «excavación arqueológica» fue dejando de ser sinónimo de "arqueología» para formar parte de un proceso más amplio, en el que tienen cabida la prospección, las cartas arqueológicas como herramientas de gestión, la difusión, la restauración, la protección, etc. como partes integrantes de un proceso arqueológico.

Partiendo de esta concepción internacional del patrimonio cultural subacuático y de una nueva realidad administrativa en España, que priorizaba la gestión del patrimonio sobre la excavación arqueológica, no es extraño que los centros de arqueología subacuática

6. La Convención 2001 de la UNESCO establece unos criterios mínimos que pueden ser mejorados por las legislaciones nacionales. Es por ello que en España, según la Ley 16/1985, la clasificación de un bien arqueológico no se realiza atendiendo a su antigüedad, sino a sus valores: «forman parte del Patrimonio Histórico Español los bienes muebles o inmuebles de carácter histórico, susceptibles de ser estudiados con metodología arqueológica» (artículo 40.1). 
que se crearon en España durante los años ochenta y noventa se plantearan como objetivo preferente la realización de las cartas arqueológicas subacuáticas como herramientas de gestión (García y Alzaga, 2008). Ejemplifica perfectamente este planteamiento el caso de Cataluña, en donde a partir de 1992, en cuanto se dispuso de una embarcación que permitiera desplazarse por toda la costa, el Thetis, se dedicaron los cuatro primeros años, única y exclusivamente, a incrementar, ahora con medios adecuados, el inventario de los yacimientos arqueológicos subacuáticos que se venía elaborando desde 1981 (Nieto y Raurich, 1997).

La gestión del patrimonio cultural requiere acciones decididas de la Administración pública mediante políticas culturales y aportaciones económicas y en los últimos años del siglo xx algunas administraciones públicas españolas se implicaron en la gestión del patrimonio cultural subacuático. Valga como prueba la creación y dotación de personal de los centros de arqueología subacuática de Cataluña, Valencia y Andalucía y del Museo Nacional, ${ }^{7}$ y la extensión del ordenamiento jurídico a los yacimientos arqueológicos subacuáticos. Algo más tarde, en 2007, el Consejo del Patrimonio Histórico —órgano de coordinación en el que figuran representantes del Estado y de todas la comunidades autónomas- aprobó un Plan Nacional de Protección del Patrimonio Cultural Subacuático Español y creó un grupo técnico de trabajo para que redactara un documento que desarrollara este plan y que acabó generando el conocido como Libro Verde (AAVV, 2010).

En la gestión del patrimonio la difusión ocupa un lugar capital y, junto a hitos excepcionales como la inauguración del museo del Vasa en 1990 o el reflote del Mary Rose en 1982 y su posterior conservación y restauración hasta la inauguración de su museo en 2013, se han multiplicado medianas y grandes exposiciones en todo el mundo, completadas con catálogos, documentales, talleres y publicaciones científicas y de divulgación. La demanda crece, especialmente con el auge del turismo subacuático, una actividad potencialmente dañina para la protección del patrimonio, pero también una oportunidad para sensibilizar al público sobre la necesidad de protegerlo. El pionero proyecto Oceanus en el Algarve portugués, las visitas a los restos sumergidos del puerto de Cesarea o al parque de Ústica o Baia, y en España las visitas a los restos del puerto sumergido de Empúries (Nieto, 2007), al barco romano del Bou Ferrer o a las excavaciones que anualmente realiza el CASC, son algunos ejemplos de estos intentos para posibilitar el acceso público a los yacimientos subacuáticos y para dar cumplimiento a las recomendaciones de la UNESCO: «Se fomentará el acceso del público al patrimonio cultural subacuático in situ, salvo en los casos en que este sea incompatible con la protección y la gestión del sitio» (Convención 2001, norma7).

7. En 1981 la Diputación de Girona creó la primera plaza de arqueólogo subacuático profesional, lo cual daría origen en 1992 a la creación oficial del Centre d'Arqueologia Subaquàtica de Catalunya (CASC). En 1982, coincidiendo con la celebración en Cartagena del VI Congreso Internacional de Arqueología Submarina, se inauguró el Museo Nacional de Arqueología Marítima y el Centro Nacional de Investigaciones Arqueológicas Submarinas. En 1996 se creó el Centro de Arqueología Subacuática de Andalucía y al año siguiente el de Valencia. 


\section{La arqueología subacuática frente al siglo XXI}

La Convención 2001 de la UNESCO consta de dos partes claramente diferenciadas, pero inseparables: su articulado y un anexo. Aun a riesgo de ser inexactos, podemos simplificar diciendo que, mientras el articulado afecta prioritariamente los Estados que han ratificado la Convención, el anexo es un conjunto de normas técnicas que regulan la actividad de los arqueólogos. Se establecen, por ejemplo, los apartados mínimos que deben contemplarse en la elaboración de un proyecto, el calendario de actuación, las competencias y titulaciones que deben reunir los miembros del equipo, las partes de que debe constar el informe final, etc. Estas normas fueron desarrolladas posteriormente y publicadas por la propia UNESCO (Maarleveld et al., 2013).

El anexo recoge, en esencia, la Carta de Sofía elaborada por ICOMOS en 1966, después de un proceso de actualización llevado a cabo por docenas de técnicos de todos los países que constituyen la UNESCO y procedentes de universidades, centros de investigación y organizaciones no gubernamentales; es por ello que este anexo tiene garantías para ser considerado un estándar de referencia para la práctica de la arqueología subacuática.

Hasta el momento, la Convención 2001 ha sido ratificada por los parlamentos de unos cincuenta países, por lo que esta norma ha entrado a formar parte de sus respectivos cuerpos legislativos. En otros países, si bien no se ha producido todavía el acto político de la ratificación parlamentaria, sí se detecta una progresiva asunción de las normas del anexo por parte de los organismos técnicos responsables de la gestión del patrimonio cultural subacuático.

En este marco y habiéndose ratificado la Convención 2001 por parte de España, es de esperar que las actuaciones arqueológicas que se realicen, desde el 3 de enero de 2009, serán acordes con esta norma y que progresivamente se irá adecuando la legislación precedente a la normativa UNESCO en aquellos artículos en los que existe discordancia.

Asumida la unidad de la arqueología terrestre y subacuática, y establecidos los estándares metodológicos de excavación y gestión, la problemática futura de la arqueología subacuática debiera venir marcada únicamente por la diferencia de medios en que ambas se desarrollan y por su desigual nivel de implantación, por lo que debería presentar una problemática conceptual y de praxis muy similar.

Si hemos dicho que los medios técnicos condicionan poderosamente los trabajos subacuáticos, hemos de aceptar que la vertiginosa evolución tecnológica actual puede facilitar poderosamente los futuros trabajos, pero se corre el riesgo de que las herramientas, la tecnología en general, se conviertan en un fin que obstaculice e incluso haga olvidar el fin último de la arqueología, que es la investigación histórica. La experiencia de Bass con el Asherab y su renuncia a este y otros complejos medios técnicos nos debería servir de ejemplo para reflexionar sobre el objetivo último que se pretende alcanzar y hacia dónde deben encaminarse los esfuerzos y los recursos. Se trata de no incurrir en el error de confundir la técnica con la ciencia. 
Esta cuestión tecnológica está íntimamente relacionada con la falsa idea de que la arqueología subacuática actual está empeñada en una carrera hacia las grandes profundidades, inaccesibles al ser humano sin un apoyo técnico complejo. Esto requiere una reflexión seria desprovista de afanes de protagonismo y de titulares de prensa, y tener muy presente la honestidad de Lamboglia al interrumpir los trabajos de la draga del Artiglio y confesar que «deseamos ser cautos y saber esperar». Esperar, pero de manera activa, como hizo Lamboglia. Hoy la tecnología ya permite una prospección arqueológica a cualquier profundidad, incluso cartografiar con precisión un pecio e incluso clasificar tipológicamente, con cierta precisión, a partir de fotografías, los objetos que no han quedado cubiertos por los sedimentos, e incluso recuperar objetos desde esas profundidades, pero se plantean serias reticencias deontológicas ante un proyecto que comporte la excavación científica total de un pecio, de un documento unitario formado por el cargamento y el casco de la embarcación, y unitario en cuanto a acto de voluntad humana que es necesario conocer en su integridad.

El auge de las redes sociales favorece caer en la tentación de la «arqueología espectáculo» para la que el patrimonio cultural subacuático se encuentra muy bien dotado, tanto por la vistosidad de los hallazgos como por el mito que rodea el mundo submarino. Además, los medios técnicos hoy disponibles —fotogrametría (fig. 10), reconstrucción virtual, impresiones 3D, etc. - nos proporcionan las herramientas necesarias. La difusión de los trabajos, y especialmente de las conclusiones, es una obligación ética de los arqueólogos, pero la difusión debe basarse en una investigación científica rigurosa, que por lo general requiere años de trabajo. Recibimos continuamente noticias, acompañadas de una documentación gráfica espectacular, sobre hallazgos y trabajos preliminares en yacimientos sobre los que pasados los meses o los años no volvemos a saber nada. Por lo general, los trabajos se interrumpen como consecuencia de la falta de un proyecto previo que haya previsto los medios económicos, técnicos y la idoneidad del equipo humano. Tras el cuarto de hora de gloria, no queda más que un yacimiento mutilado. Es por ello que, acertadamente, la Convención 2001 de la UNESCO insiste en varios de sus artículos: «Las actividades dirigidas al patrimonio cultural subacuático deberán servirse de técnicas y métodos de exploración no destructivos, que deberán preferirse a la recuperación de objetos» (norma 4 del anexo).

Si podemos considerar, a efectos científicos, una excavación arqueológica no publicada como una excavación no realizada, las consecuencias son más desastrosas, dado que la excavación supone la destrucción del yacimiento, por lo que esta no tiene justificación si no aporta un conocimiento científico y un aprovechamiento social. Este es un mal común a la arqueología realizada tanto en el medio terrestre como en el subacuático, y tanto a las excavaciones programadas como, y especialmente, a las preventivas y de urgencia. Las causas, a las que hay que buscar urgentes soluciones, son múltiples, pero todas ellas deberían se inadmisibles en el siglo xxI.

Algo que parece que está cambiando, aunque no con la celeridad que sería necesaria, es la formación, tanto de los arqueólogos subacuáticos como de la sociedad. Algunos 


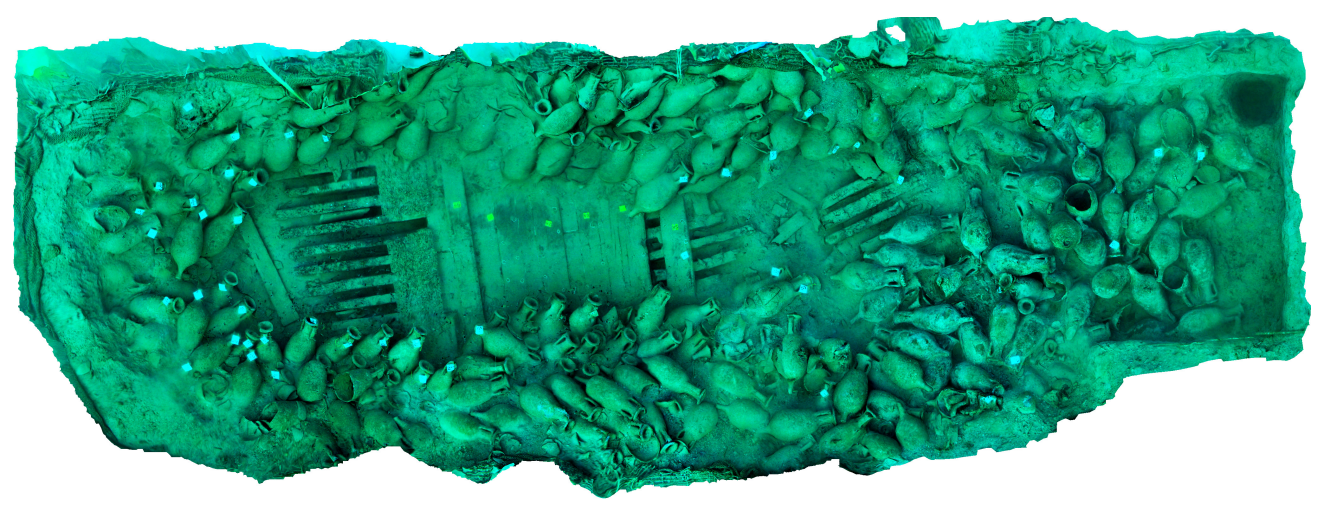

Figura 10. Ortofotografía por fotogrametría realizada, a partir de 1200 fotografías, en 2016 en el pecio Bou Ferrer (Vilajoyosa Alicante) (imagen en Moya, 2017).

indicios nos hacen ser optimistas y esperar que en los próximos años se produzcan importantes avances en este campo, al menos en nuestra área socioeconómica. En las últimas décadas, buena parte de la sociedad y especialmente los medios de comunicación han pasado de considerar al "cazatesoros» submarino como un héroe para calificarlo de "pirata». En cuanto a los técnicos, disponemos ya de un buen número de arqueólogos con una formación teórica en arqueología náutica e historia marítima y con la posibilidad de hacer arqueología bajo las aguas. La formación ha sido irregular, escasamente reglada y especialmente protagonizada por museos, centros de arqueología subacuática y universidades, mediante asistencia a excavaciones o cursos teóricos esporádicos de insuficiente duración. Las universidades se han incorporado tarde a la formación teórica y práctica en esta disciplina, especialmente en nuestro país. ${ }^{8}$ Son referentes las universidades de Texas, Southampton, Aix-Marsella y Cádiz, con cursos continuados de máster y de doctorado.

Es de destacar un valor añadido de estos cursos universitarios y es el de haber normalizado y oficializado el cursus honorum ${ }^{9}$ de los arqueólogos subacuáticos, lo que posibilita la entrada de la disciplina en las universidades y facilita la formación de nuevas generaciones.

Hay que ser precavidos en el tipo de formación que se proporciona a los nuevos arqueólogos. Sería un error formar arqueólogos subacuáticos; hay que formar arqueólogos y especializarlos más tarde. Unos conocimientos amplios de historia, no solo marítima, y una experiencia en excavaciones terrestres son esenciales, como lo es para un arqueólogo terrestre, al menos, una formación teórica en historia marítima.

8. Cabe recordar los cursos de doctorado de la Universidad de Zaragoza, los de posgrado y máster de la Universidad de Barcelona celebrados de 2005 a 2008 (Nieto y Cau, 2009), y los cursos de verano de la Universidad de Murcia.

9. En estos momentos, en España, además de varios centenares de arqueólogos que tienen ya una formación teórica y práctica en arqueología subacuática, existe alrededor de una docena de arqueólogos que practican habitualmente la arqueología subacuática, que tienen ya el título de doctor; incluso uno ha obtenido recientemente la más prestigiosa y disputada beca de formación posdoctoral, la Juan de la Cierva. Esto posibilita la incorporación de estos doctores a la vida universitaria profesional como docentes e investigadores y seguir una carrera universitaria normalizada, convirtiéndose en difusores y potenciadores de esta disciplina ante las nuevas generaciones. 
Es en este campo de la formación en el que incide la Convención 2001 en su artículo 21: «Los Estados parte cooperarán para impartir una formación en arqueología subacuática, en las técnicas de preservación del patrimonio cultural subacuático y, conforme a los términos acordados, en la transferencia de tecnologías relacionadas con el patrimonio cultural subacuático».

Los beneficios de esta formación debieran generar a medio y largo plazo un cambio de mentalidad, tanto en los gestores públicos del patrimonio arqueológico como en la sociedad, lo cual redundaría en una mejor protección de este patrimonio cultural y un mejor aprovechamiento social. Es comprensible, pero sintomático, que nuestros museos de arqueología se encuentren focalizados en la arqueología terrestre y que todavía, en muchos casos, los objetos subacuáticos se descontextualicen para ser aprovechados por sus características estéticas y su grado de integridad, con el fin de completar las muestras o las tipologías. Este es un debate que se producirá en los próximos años, una vez aceptada la complementariedad de los datos aportados por los yacimientos terrestres y los subacuáticos para un conocimiento más preciso de las sociedades pretéritas.

Algunos, los impacientes, especialmente los jóvenes, considerarán que hemos avanzado poco. Otros consideramos que la velocidad ha sido vertiginosa desde aquel 21 de febrero de 1950 en que Lamboglia tomo la decisión de desterrar la draga del Artiglio para hacer arqueología subacuática. Han trascurrido menos de setenta años, un tiempo insignificante para el desarrollo y la consolidación de cualquier actividad científica. La celeridad en el desarrollo de la actividad quizá podamos encontrarla tanto en el hecho de que la arqueología subacuática se ha beneficiado de siglos de actividad en tierra, que originó una epistemología que ha heredado la arqueología realizada bajo las aguas, como en los vertiginosos progresos tecnológicos que han facilitado enormemente los trabajos subacuáticos.

\section{Bibliografía}

AAVV, 2010, Libro verde: Plan Nacional de Protección del Patrimonio Cultural Subacuático Español, Madrid.

ALFARAS, R., 1894, Pesca de ánforas, Boletín de la Asociación Artístico-Arqueológica de Barcelona 4 (40), Barcelona, 17-21.

AZNAR, M., 2008, La definición del patrimonio cultural subacuático en la Convención UNESCO de 2001, Boletín del Instituto Andaluz del Patrimonio Histórico 67, Sevilla 100-109.

BASS, G., 1966, Archaeology under water, Nueva York.
BASS, G., 1972, A history of Seafaring, based on underwater archaeology, Nueva York.

BASS, G. y Van DOORNINCK, F. H., 1982, Yassi Ada Volume 1. A Seventh-Century Byzantine Shipwreck, College Station, Texas.

GARCIA, C. y ALZAGA, M., 2008, La carta arqueológica subacuática de Andalucía como instrumento para la tutela de un patrimonio emergente, en Mainake 30, Málaga, 129-143.

GIANFROTTA, P. y POMEY, P., 1981, Archeologia subacquea: storia, tecniche, scoperte e relitti, Milán. 
GRENIER, R., BERNIER, M. y STEVENS, W., 2007, L'archéologie subaquatique de Red Bay. La construction navale et la pêche de la baleine basques au $X V I^{e}$ siècle, Otawa.

HESNARD, A., 2011, L'épave de la Madrague de Giens (Var) et la plaine de Fondi (Latium): producteurs de vins, d'amphores Dr.1B et commerçants, en Archaeonautica 17, Aix-en-Provence,71-93.

LAMBOGLIA, N., 1950, Gli scavi di Albintimilium e la cronología della cerámica romana, Bordighera.

LAMBOGLIA, N., 1952, La nave romana de Albenga, Rivista di Studi Liguri XVIII, 3-4, 131-236.

LAMBOGLIA, N., 1961a, Lo stato attuale dell'archeologia sottomarina in Italia, Actas del II Congresso Internazionale di Archeologia Sottomarina (Albenga, 1958), Bordiguera, 12-17.

LAMBOGLIA, N., 1961b, La nave romana di Spargi (La Maddalena). Campagna di scavo 1958, Actas del II Congresso Internazionale di Archeologia Sottomarina (Albenga, 1958), Bordiguera, 143-166.

LAMBOGLIA, N., 1964, Il primo saggio di scavo sulla nave romana di Albenga, Rivista di Studi Liguri 30, 219-228.

LEJEUNE, M., POUILLOUX, J. y SOLIER, Y., 1988, Étrusques et ionien archaïques sur un plomb de Pech Mao, Revue Archéologique de Narbonnaise 21, 19-59

L'HOUR, M., 2012, De L'Archéonaute à l'André Malraux, Arles.

MAARLEVELD, T., GUÉRIN, U. y EGGER, B., 2013, Manual para las actividades dirigidas al Patrimonio Cultural Subacuático: directrices para el Anexo de la Convención de la UNESCO 2001, París.

MERLIN, A. y POINSSOT, L., 1930, Cratères et candélabres de marbre trouvés en mer prés de Mahdia, París.
MOYA, J. A., 2017, Fotografía y fotogrametría subacuática aplicadas al patrimonio cultural sumergido. Alicante.

NIETO, X., 1984, Introducción a la arqueología subacuática, Barcelona.

NIETO, X., 1997, Le commerce de cabotage et de redistribution, en P. GIANFROTTA, X. NIETO, P. POMEY y A. TCHERNIA, 1997, La navigation dans l'Antiquité, Aix-en-Provence, 147-159.

NIETO, X., 2007, Problemática de la visita pública de los yacimientos arqueológicos subacuáticos: el caso del puerto de Ampurias, Comunicare la memoria del Mediterraneo, (ANSER), Pisa, 125-130.

NIETO, X. y CAU, M. A. (eds.), 2009, Arqueología nàutica mediterrània, Girona.

NIETO, X. y RAURICH, X., 1997, La carta arqueològica subaquàtica de Catalunya; recerca i gestió, Tribuna de Arqueologia 1995-1996, Barcelona, 21-38.

RAURICH, X., 1994, El jaciment de Cala Cativa: notes sobre el primer treball d'arqueologia subaquàtica realitzat a Catalunya, Annals de l'Institut d'Estudis Empordanesos 27, Figueres, 262-271.

REBIKOFF, D., 1961, Restitution photografique stéréoscopique des épaves inmergées, Actas del II Congresso Internazionale di Archeologia Sottomarina (Albenga 1958), Bordighera, 291-293.

SANMARTÍ, E. y SANTIAGO, R. A., 1988, La lettre greque d'Emporion et son contexte archèologique, Revue Archeologique de Narbonnaise 21, 3-17.

TCHERNIA, A., POMEY, P. y HESNARD, A., 1978, L'épave romaine de la Madrague de Giens (Var). Campagnes 1972-1975, en XXXIV suplemento a Gallia, París. 
